\title{
A Wideband Circularly Polarized Antenna with Characteristic Mode Analysis
}

\author{
Lei Chang $\mathbb{D},{ }^{1}$ Ling-Lu Chen $\mathbb{D}^{1},{ }^{1}$ Jian-Qiang Zhang, ${ }^{1}$ and Dan $\mathrm{Li}^{2}$ \\ ${ }^{1}$ No. 36 Research Institute of CETC, Jiaxing 314033, China \\ ${ }^{2}$ Academician Workstation of Zhejiang Longyou Gongren Electronics Co., Ltd., Quzhou, Longyou 324014, China \\ Correspondence should be addressed to Lei Chang; yutian_1986@163.com
}

Received 14 March 2020; Revised 11 May 2020; Accepted 19 May 2020; Published 12 June 2020

Academic Editor: Hervé Aubert

Copyright (c) 2020 Lei Chang et al. This is an open access article distributed under the Creative Commons Attribution License, which permits unrestricted use, distribution, and reproduction in any medium, provided the original work is properly cited.

A wideband circularly polarized (CP) antenna is presented to achieve enhanced impedance, axial ratio (AR), and gain bandwidths. The antenna consists of two circular patches, a split-ring microstrip line with six probes, and a circular ground plane. By using these six probes which are placed in sequence on the split-ring microstrip line, the operating bandwidth of the proposed antenna is increased. The characteristic mode method is used to analyze different modes of the antenna and reveal the mechanism of extending the 3-dB AR bandwidth. Measured results show that the proposed antenna obtains an impedance bandwidth of $1.486-2.236 \mathrm{GHz}(40.3 \%)$ for $S_{11} \leq-18 \mathrm{~dB}$, a $3-\mathrm{dB}$ AR bandwidth of $1.6-2.2 \mathrm{GHz}$ (31.6\%), and a boresight gain of $8.89 \pm 0.87 \mathrm{dBic}$.

\section{Introduction}

With the development of many wireless systems, such as radar, satellite communication, remote control, and telemetry systems, there are more and more applications of circularly polarized (CP) antennas because $\mathrm{CP}$ antennas allow for reduction of multipath fading, avoiding polarization mismatching, and better weather adaptability. A $\mathrm{CP}$ annular-ring microstrip antenna using an equal-split power divider is proposed in [1], which has a $3-\mathrm{dB}$ axial ratio (AR) bandwidth of $6 \%$. A CP antenna fed by an L-probe is presented with a $3-\mathrm{dB}$ AR bandwidth of $9 \%$, which uses two stacked folded patches [2]. A square ring slot including four branch slots is applied to produce circular polarization, and a $3-\mathrm{dB}$ AR bandwidth of $8.7 \%$ is achieved [3].

However, there is a growing demand for antennas with a wideband AR bandwidth. Therefore, it is necessary to investigate methods of extending AR bandwidth. In [4], an air gap is used to a stacked patch with a single probe feed to enhance the AR bandwidth (20.2\%). A coplanar parasitic ring slot patch is introduced to achieve good circular polarization performance with a 3-dB AR bandwidth of $16 \%$ [5]. By using an $\mathrm{H}$-shaped patch and a probe in conjunction with a printed monopole, a 3-dB AR bandwidth of $19.4 \%$ is obtained [6]. Based on the meandering feed structures, patch antennas are studied to achieve wide 3-dB AR bandwidths [7-9]. 3-dB AR bandwidths of $13.5 \%$ [7], 22.4\% [8], and $16.8 \%$ [9] are achieved by using a horizontally meandered strip, a 3D meandering strip, and a printed meandering probe, respectively. In [10], a driven patch with a square ring, a $270^{\circ}$ loop of microstrip line, and an L-shaped parasitic patch is used to excite four square parasitic patches to achieve a 3$\mathrm{dB}$ AR bandwidth of $28.1 \%$. By using a differentially fed method, a 3-dB AR bandwidth of $31 \%$ is obtained [11]. The $\mathrm{CP}$ antenna using an $\mathrm{n}$-shaped proximity coupling probe configuration has the impedance and $3-\mathrm{dB} A R$ bandwidths of $25 \%$ [12]. In [13], a quasi-magnetic-electric CP patch antenna with a single feed is studied, which can achieve a 3-dB AR bandwidth of $15.3 \%$. An H-shaped microstrip patch and a reactive impedance surface are applied to improve the $3-\mathrm{dB}$ AR bandwidth to $27.5 \%$ [14]. Sequential feed methods are also proposed to achieve good circular polarization performance [15-20]. In [15], four cross slots via a microstrip feed line with multiple matching segments are used to excite a square patch, and a 3 -dB AR bandwidth of $16 \%$ is achieved. Four asymmetric 


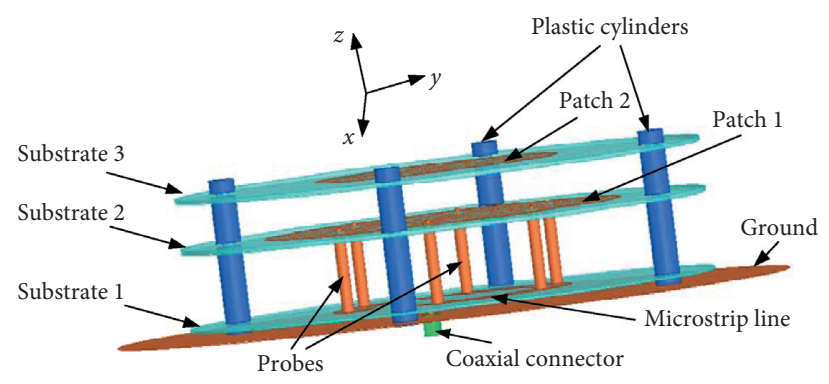

(a)

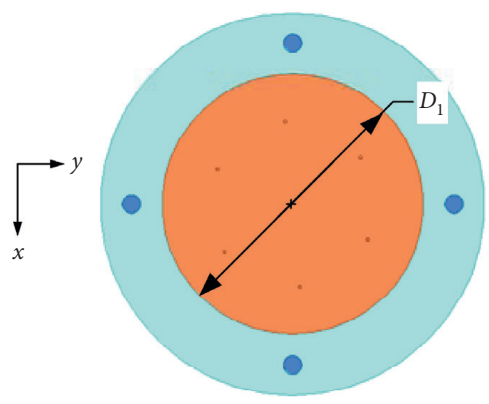

(c)

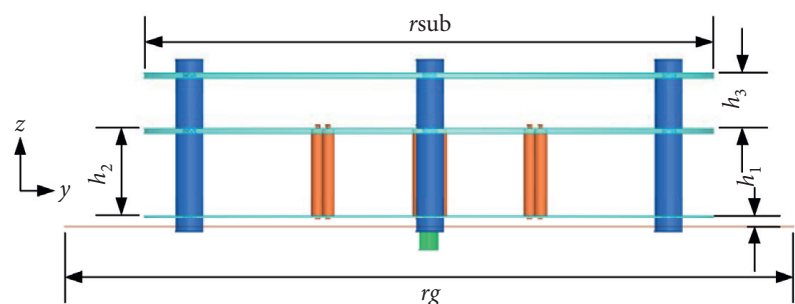

(b)

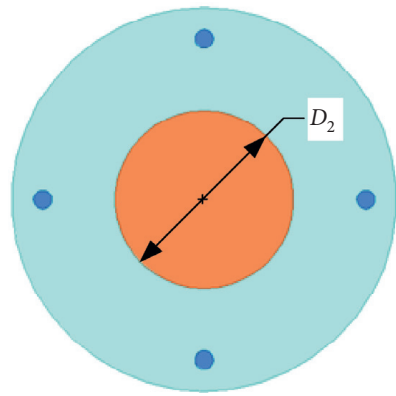

(d)

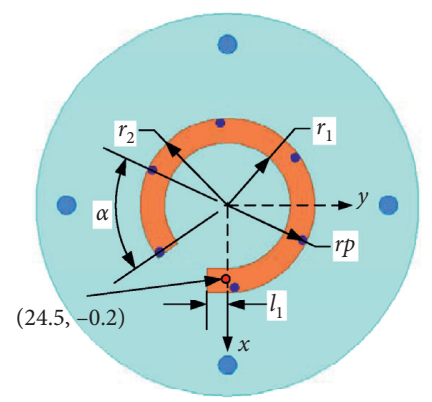

(e)

Figure 1: Geometry of the proposed antenna. (a) 3D view, (b) side view, (c) patch 1, (d) patch 2, and (e) microstrip line.

TABLE 1: Dimensions of the proposed antenna.

\begin{tabular}{lc}
\hline Parameters & Value \\
\hline$D 1$ & $85 \mathrm{~mm}$ \\
$r 1$ & $20.5 \mathrm{~mm}$ \\
$r p$ & $27 \mathrm{~mm}$ \\
$h 1$ & $2.4 \mathrm{~mm}$ \\
$h 3$ & $12 \mathrm{~mm}$ \\
$r g$ & $160 \mathrm{~mm}$ \\
$D 2$ & $58 \mathrm{~mm}$ \\
$r 2$ & $28.5 \mathrm{~mm}$ \\
$l 1$ & $8.5 \mathrm{~mm}$ \\
$h 2$ & $19 \mathrm{~mm}$ \\
$\alpha$ & $60^{\circ}$ \\
$r s u b$ & $145 \mathrm{~mm}$ \\
\hline
\end{tabular}

cross slots and a microstrip ring with eight matching segments are applied to obtain an enhanced 3-dB AR bandwidth of $26 \%$ [16]. Two coin-shaped patches and a sequential feed structure using four probes are presented in [17], and a 3-dB AR bandwidth of $15.9 \%$ is achieved. The 3-dB AR bandwidth is enhanced by using a ring- shaped strip inlaid along the edge of the parasitic patch and two square holes in the center of the main patch and the parasitic one. In [18], a sequential feed structure using four probes which are connected to a microstrip feed line is applied to achieve a wide 3-dB AR bandwidth (16.4\%). Two probes connected to a horizontal L-shaped strip are as a sequential feed structure, and a shorting pin is loaded to enhance the 3-dB AR bandwidth (17.9\%) [19]. In [20], four slot elements fed by a 4-way sequential-phase feeding network is proposed to achieve a $3-\mathrm{dB}$ AR bandwidth of $15.6 \%$.

In this paper, a wideband right-hand circular polarization (RHCP) antenna with two circular patches and a sequential feed structure is presented. By increasing the number of probes of the sequential feed structure from 4 to 6 , the impedance and 3-dB AR bandwidths are improved. The effects of the number of probes on the antenna performance are analyzed by the characteristic mode (CM) method. The proposed antenna exhibits a 3-dB AR bandwidth of $1.6-2.2 \mathrm{GHz}(31.6 \%)$ and a good impedance matching performance in the band of $1.486-2.236 \mathrm{GHz}$ $(40.3 \%)$ for $S_{11} \leq-18 \mathrm{~dB}$. 


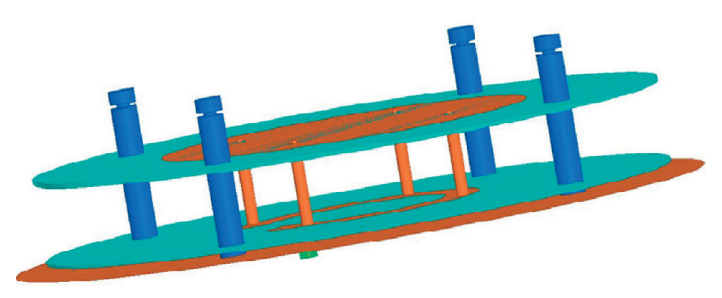

(a)

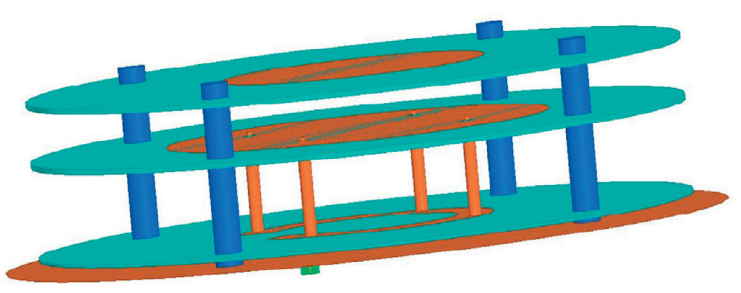

(b)

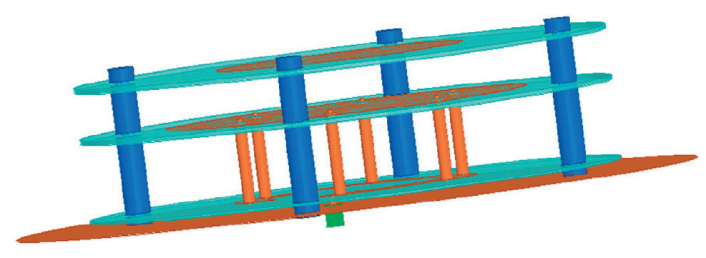

(c)

Figure 2: Three CP antennas. (a) Antenna 1. (b) Antenna 2. (c) Proposed antenna.

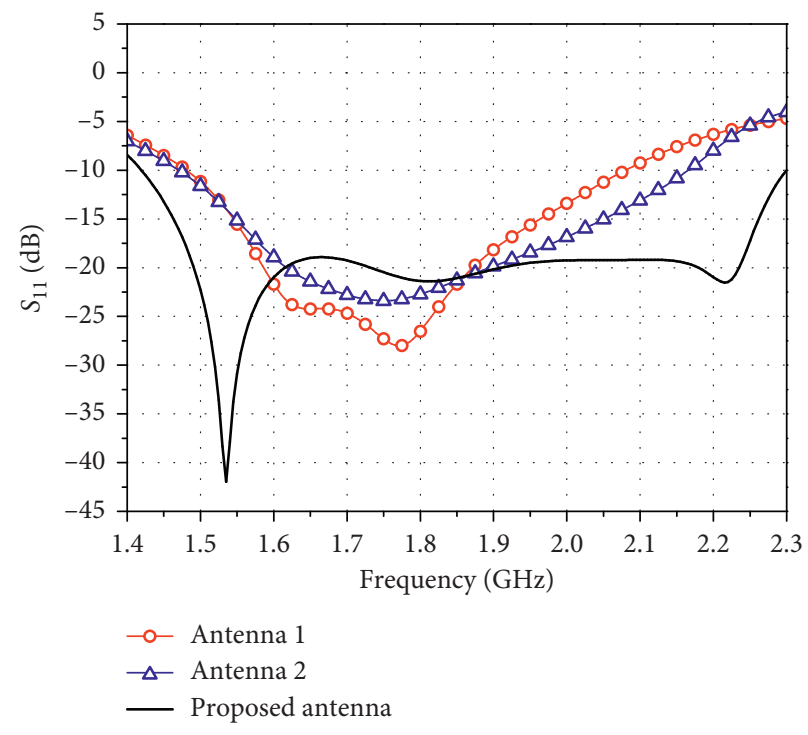

(a)

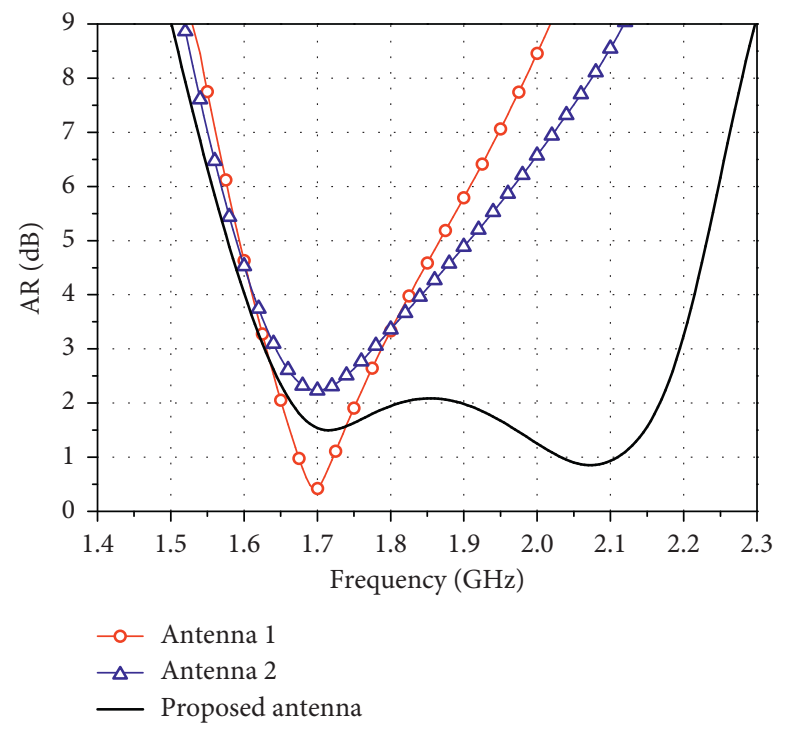

(b)

Figure 3: Simulated results of the three CP antennas. (a) $S_{11}$ and (b) AR.

\section{Antenna Design}

The geometry of the proposed antenna is depicted in Figure 1 , and the simulated results are obtained by using HFSS. The diameters of patch 1 and patch 2 are $D_{1}$ and $D_{2}$, respectively. The distance between the two patches is $h_{3}$. The inner and outer radii of the split-ring microstrip line are $r_{1}$ and $r_{2}$, respectively. The beginning of the split-ring microstrip line contains a rectangular section with length $l_{1}$. The rectangular section is introduced to enhance the impedance bandwidth. The distance between patch 1 and the split-ring microstrip line is $h_{2}$. The split-ring microstrip line, patch 1 , and patch 2 are printed on the substrate $\mathrm{F}_{4} \mathrm{BMX} 220$ with $\varepsilon_{\mathrm{r}}=2.2$ and $\tan \delta=0.0007$. Substrate 1 , substrate 2 , and substrate 3 have a thickness of $0.5 \mathrm{~mm}, 1 \mathrm{~mm}$, and $1 \mathrm{~mm}$, respectively. The diameter of the three substrates is $r s u b$. Six probes with a diameter of $2.8 \mathrm{~mm}$ are used to feed patch 1 , which are placed in sequence on the split-ring microstrip line. The probes are distributed along an arc line with radius $r p$. The angle between the two adjacent probes is $\alpha$. The number of probes and the angle $\alpha$ affect the CP performance and impedance bandwidth greatly. The diameter of the ground is $r g$. The distance between the ground and the splitring microstrip line is $h_{1}$. The detailed dimensions of the proposed antenna are shown in Table 1.

Three prototypes of the $\mathrm{CP}$ antennas are created to exhibit the design process of the proposed antenna, as shown in Figure 2. Antenna 1 has four probes and no parasitic patch. Antenna 2 includes a circular parasitic patch. The proposed antenna contains six probes and a circular parasitic patch. The simulated $S_{11}$ and boresight AR of the three $\mathrm{CP}$ antennas are shown in Figure 3.

For antenna 1, by using the sequential feed structure with four probes, the RHCP wave is obtained. Antenna 1 achieves 


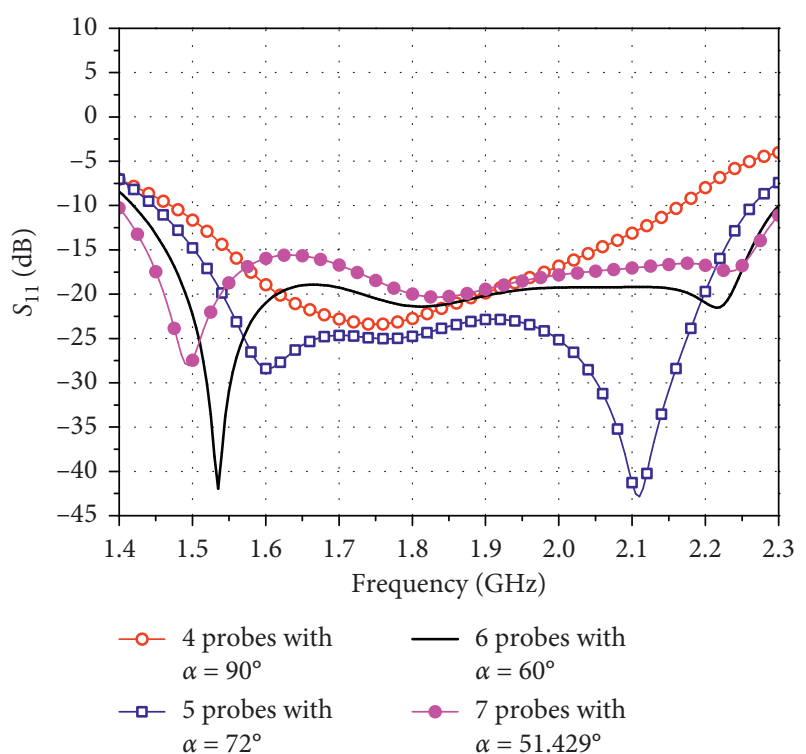

(a)

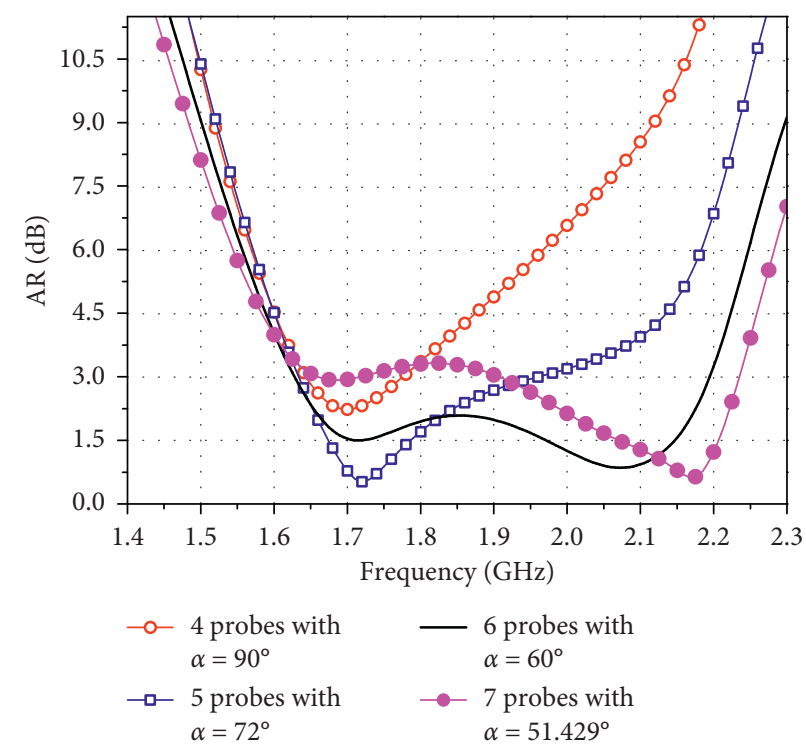

(b)

FIgURE 4: Effects of the number of probes on (a) $S_{11}$ and (b) AR.

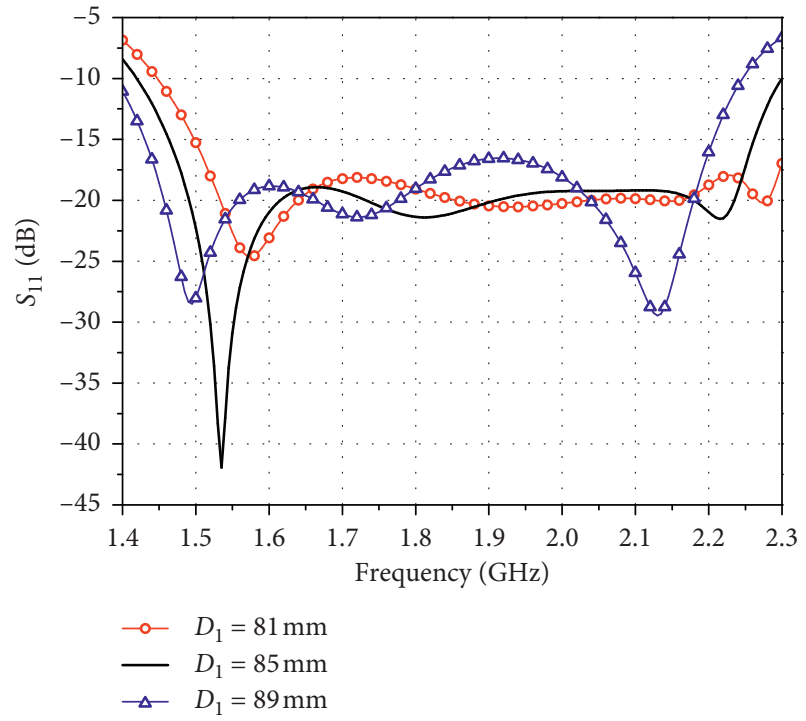

(a)

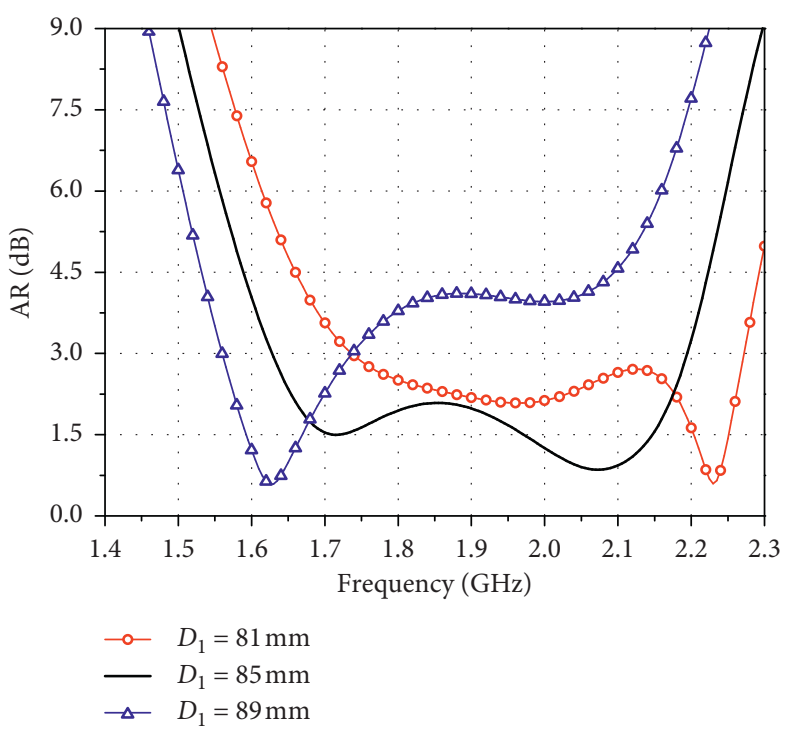

(b)

FIguRE 5: Effects of the diameter $D_{1}$ of patch 1 on (a) $S_{11}$ and (b) AR.

an impedance bandwidth of $19.28 \%$ for $S_{11} \leq-18 \mathrm{~dB}$ and 3 $\mathrm{dB}$ AR bandwidth of $9.36 \%$. The impedance and 3-dB AR bandwidths are still narrow.

By adding a parasitic patch, the impedance bandwidth of antenna 2 is increased to $21.41 \%$ for $S_{11} \leq-18 \mathrm{~dB}$. The 3$\mathrm{dB}$ AR bandwidth is only $8.19 \%$. However, the AR of antenna 2 in the band of $1.8-2.3 \mathrm{GHz}$ is better than that of antenna 1 .

For the proposed antenna, the number of the probes is increased from 4 to 6 , and the impedance and $3-\mathrm{dB} A R$ bandwidths are improved to $41 \%(1.483-2.247 \mathrm{GHz})$ for
$S_{11} \leq-18 \mathrm{~dB}$ and $29.6 \%(1.628-2.193 \mathrm{GHz})$. It can be observed that the number of probes has a significant effect on the impedance and 3-dB AR bandwidths.

2.1. Effects of the Number of Probes. We study the performance of the antenna when the number of probes is $4,5,6$, and 7 with $\alpha=90^{\circ}, 72^{\circ}, 60^{\circ}$, and $51.429^{\circ}$, respectively, as shown in Figure 4. For traditional four probes with $\alpha=90^{\circ}$, the $3-\mathrm{dB}$ AR bandwidth is only $7.8 \%$ and the impedance bandwidth for $S_{11} \leq-18 \mathrm{~dB}$ is $21.2 \%$. To extend the $3-\mathrm{dB}$ 


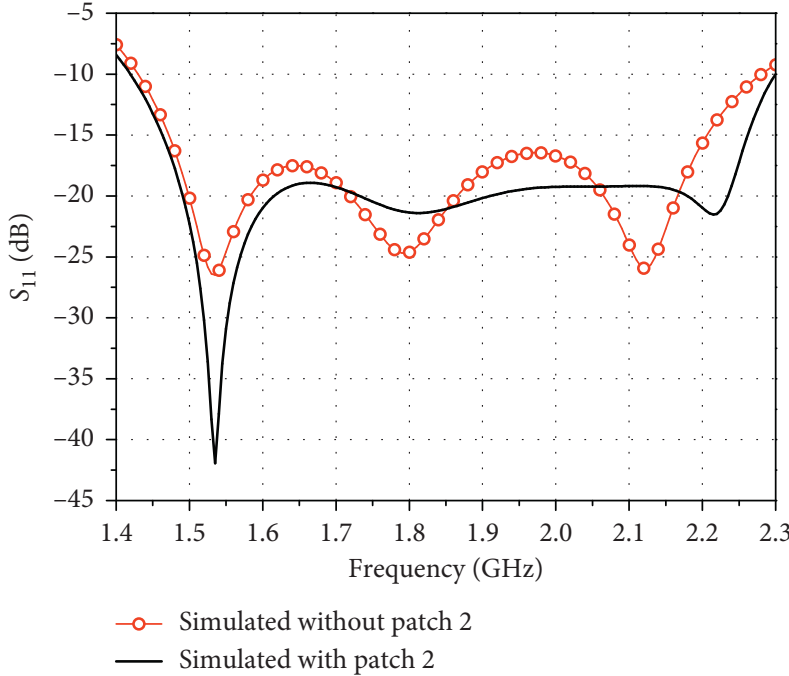

(a)

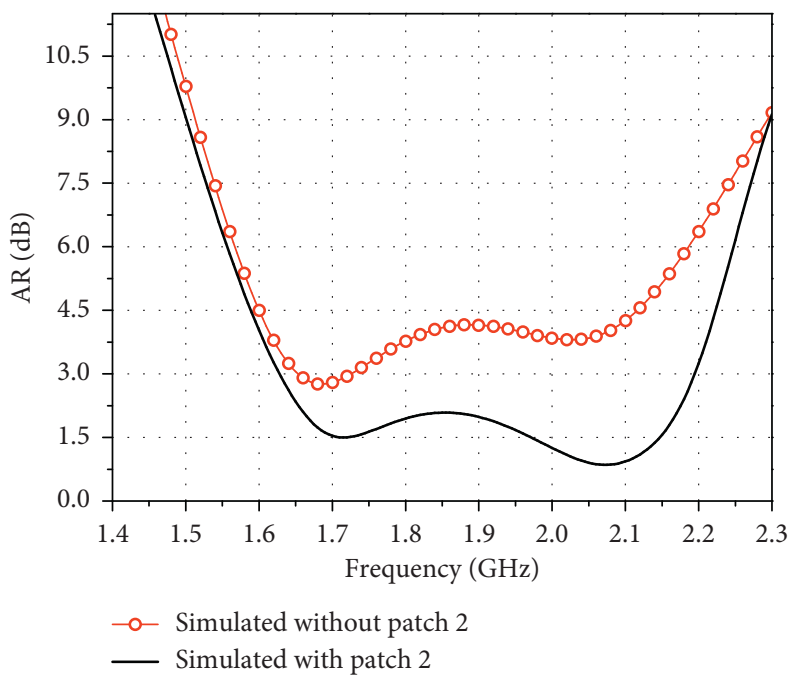

(b)

Figure 6: Effects of patch 2 on (a) $S_{11}$ and (b) AR.

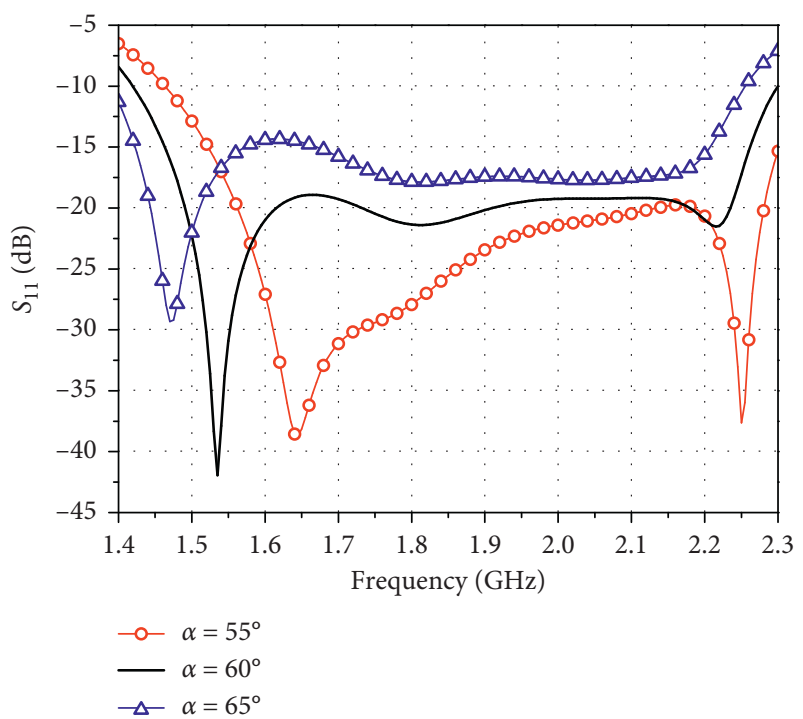

(a)

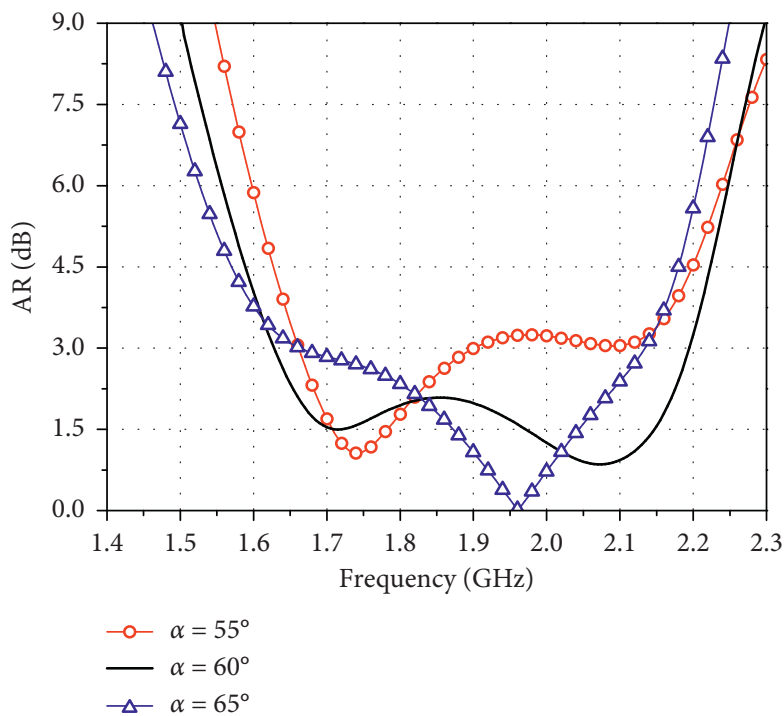

(b)

FIgURE 7: Effects of the angle $\alpha$ on (a) $S_{11}$ and (b) AR.

AR bandwidth, we proposed a new method to achieve an enhanced AR bandwidth by increasing the number of probes.

When five probes with $\alpha=72^{\circ}$ are used, the impedance bandwidth for $S_{11} \leq-21 \mathrm{~dB}$ is $34.6 \%(1.547-2.194 \mathrm{GHz})$. However, the $3-\mathrm{dB}$ AR bandwidth is only $18.3 \%$. The impedance bandwidth of $41 \%$ for $S_{11} \leq-18 \mathrm{~dB}$ and the 3$\mathrm{dB}$ AR bandwidth of $29.6 \%$ are achieved when six probes with $\alpha=60^{\circ}$ are introduced. As the number of probes increases to seven $\left(\alpha=51.429^{\circ}\right)$, the impedance matching becomes worse and the 3-dB AR bandwidth is only $15.9 \%$.

2.2. Effects of Patch 1 and Patch 2. Patch 1 is a main radiation patch, and patch 2 is a parasitic patch. The simulated results of $S_{11}$ and AR by varying $D_{1}$ are shown in Figure 5 . As $D_{1}$ increases, the operating frequency band of the antenna is shifted to a lower frequency. 


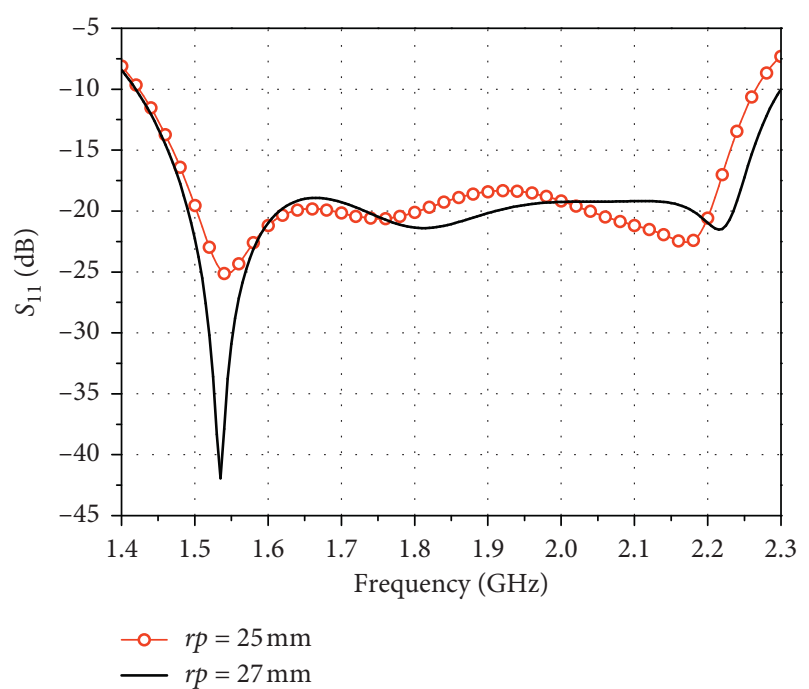

(a)

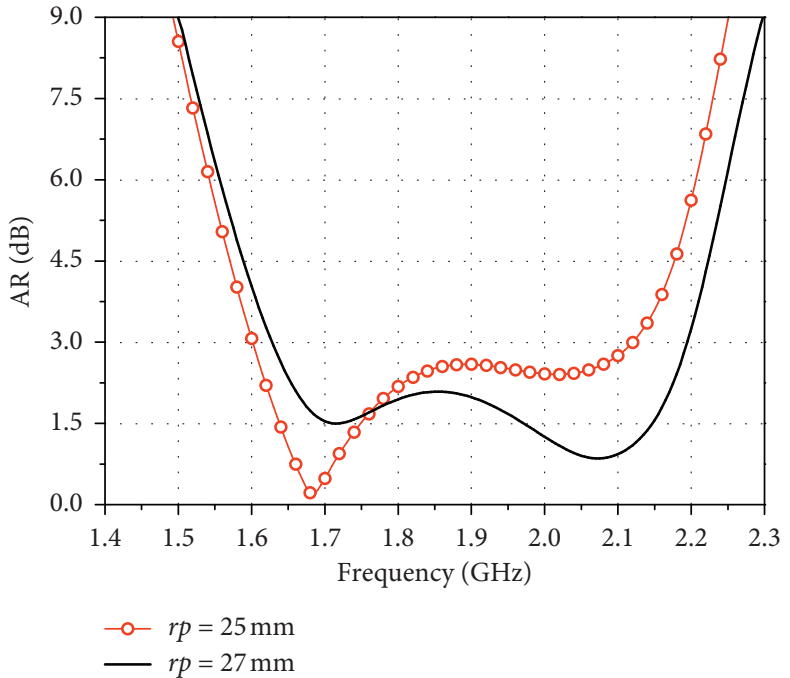

(b)

FIgUre 8: Effects of the radius $r p$ on (a) $S_{11}$ and (b) AR.

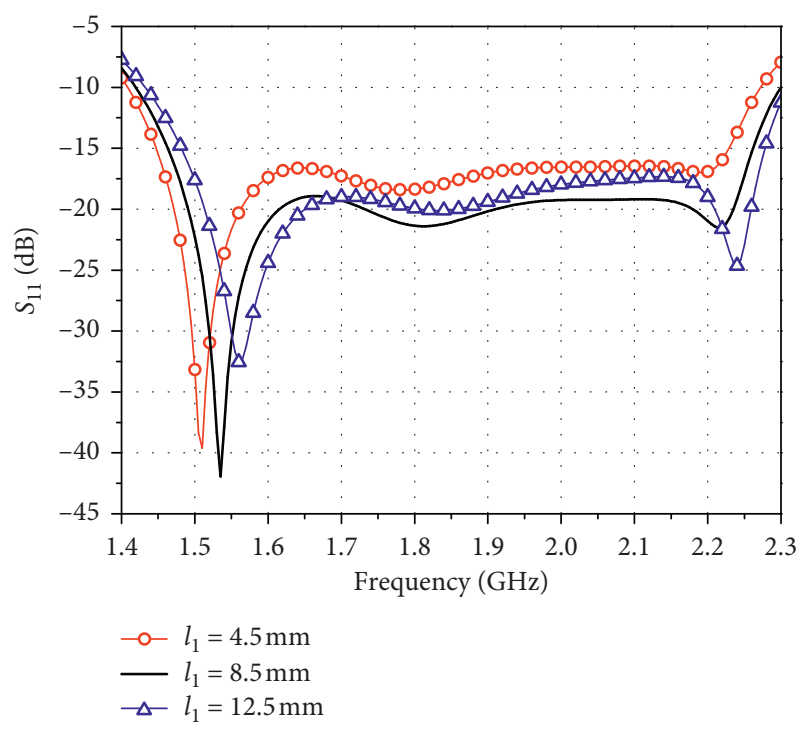

(a)

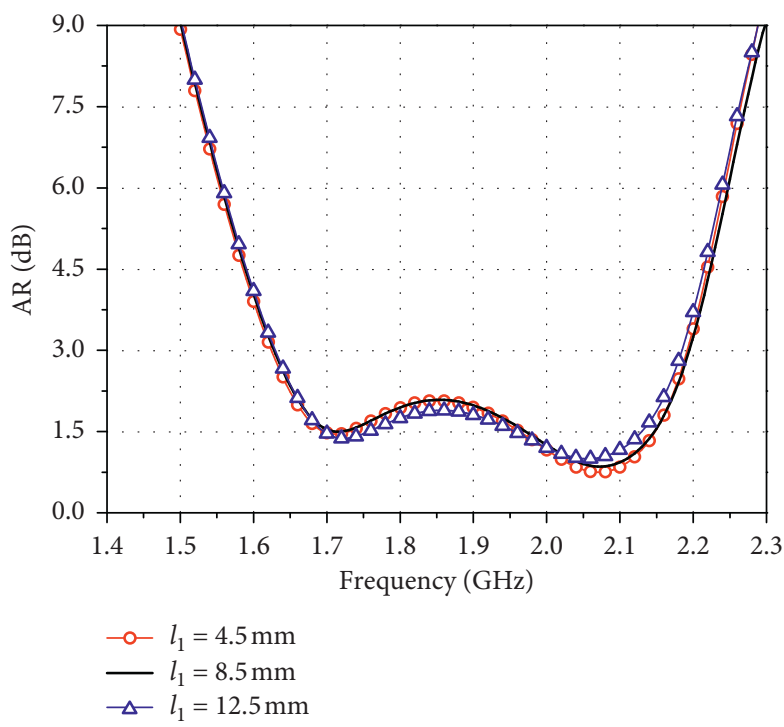

(b)

FIgURE 9: Effects of the length $l_{1}$ on (a) $S_{11}$ and (b) AR.

Figure 6 shows the effects of patch 2 on the performance of $S_{11}$ and boresight AR. It is shown that patch 2 has a significant effect on the AR, especially in the high-frequency band.

2.3. Effects of the Sequential Feed Structure. The parameters of the angle $\alpha$, the length $l_{1}$, and the radius $r p$ are investigated to further illustrate the antenna design process.

The effects of the angle $\alpha$ on the performance of $S_{11}$ and boresight AR are shown in Figure 7. It is shown that the maximum value of $S_{11}$ in the band of $1.55-2.25 \mathrm{GHz}$ is increased and the low cutoff frequency is shifted to a lower frequency as the angle $\alpha$ increases. Decreasing $\alpha$ makes the
AR become worse in the high-frequency band. Thus, $\alpha=60^{\circ}$ was chosen.

As shown in Figure 8(a), the radius $r p$ has a slight effect on the impedance matching. However, the AR in the band of $1.8-2.2 \mathrm{GHz}$ becomes worse as $r p$ decreases, as shown in Figure 8(b).

The effects of the length $l_{1}$ of the rectangular section on the split-ring microstrip line are shown in Figure 9. The length $l_{1}$ has a slight effect on the AR. Compared with $l_{1}=8.5 \mathrm{~mm}$, the impedance bandwidth is shifted down and the impedance matching in the band of $1.6-2.2 \mathrm{GHz}$ becomes worse with $l_{1}=4.5 \mathrm{~mm}$; while with $l_{1}=12.5 \mathrm{~mm}$, the impedance matching in the band of $1.7-2.2 \mathrm{GHz}$ becomes worse. 


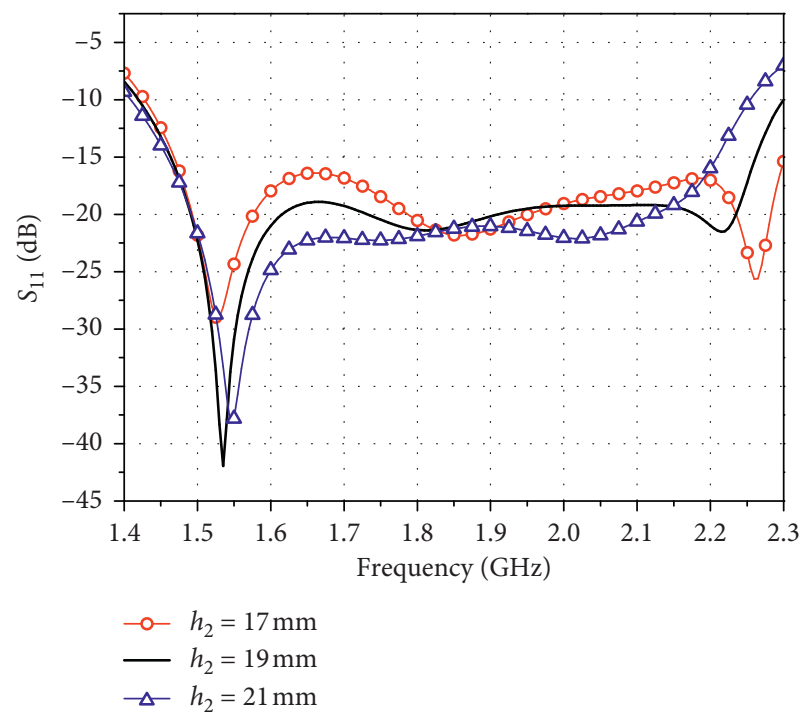

(a)

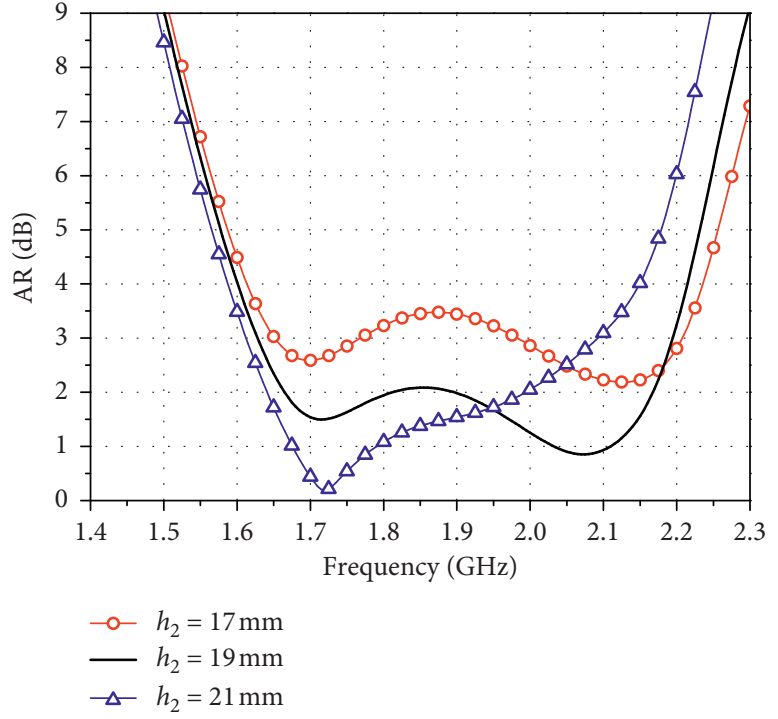

(b)

FIGURE 10: Effects of the height $h_{2}$ on (a) $S_{11}$ and (b) AR.

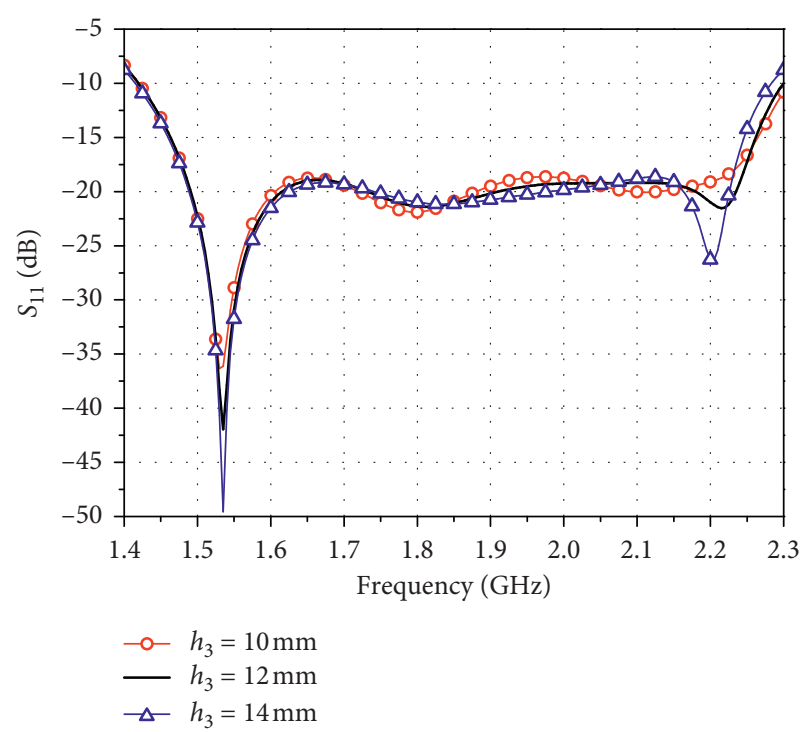

(a)

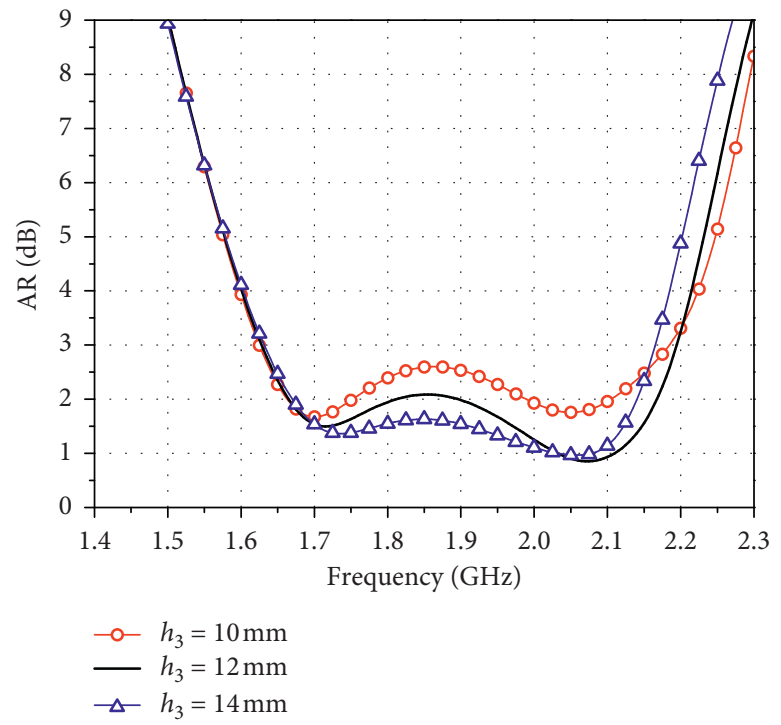

(b)

FIgURE 11: Effects of the height $h_{3}$ on (a) $S_{11}$ and (b) AR.

2.4. Effects of the Height $h_{2}$ and $h_{3}$. The effects of varying height of patch 1 and patch 2 on the performance of $S_{11}$ and boresight $\mathrm{AR}$ are shown in Figures 10 and 11, respectively.

As the height $h_{2}$ decreases, the impedance matching and boresight AR in the operating band get worse. Increasing $h_{2}$ makes the impedance matching and boresight AR better, but narrows the operating bandwidth.

A slight effect of the height $h_{3}$ on the impedance matching has been observed. However, the height $h_{3}$ has a significant effect on the boresight AR. Increasing $h_{3}$ greatly degrades the $3-\mathrm{dB}$ AR bandwidth. When $h_{3}$ is reduced to $10 \mathrm{~mm}$, the boresight $A R$ deteriorates in the operating band.
Figure 12 shows the surface current distribution on patch 1 and patch 2 at $1.91 \mathrm{GHz}$. It is obvious that the vector current rotates counterclockwise in a circular path, which depicts RHCP.

2.5. Characteristic Mode Analysis (CMA). In order to illustrate the operating principle of the antenna, CMA is carried out using FEKO.

When four probes with $\alpha=90^{\circ}$ are used, the mode current distribution at 1.72 and $1.96 \mathrm{GHz}$ is shown in Figure 13. Figure 13(a) shows that mode 1 is orthogonal to modes 3 and 4 at $1.72 \mathrm{GHz}$. Thus, the $\mathrm{CP}$ radiation 


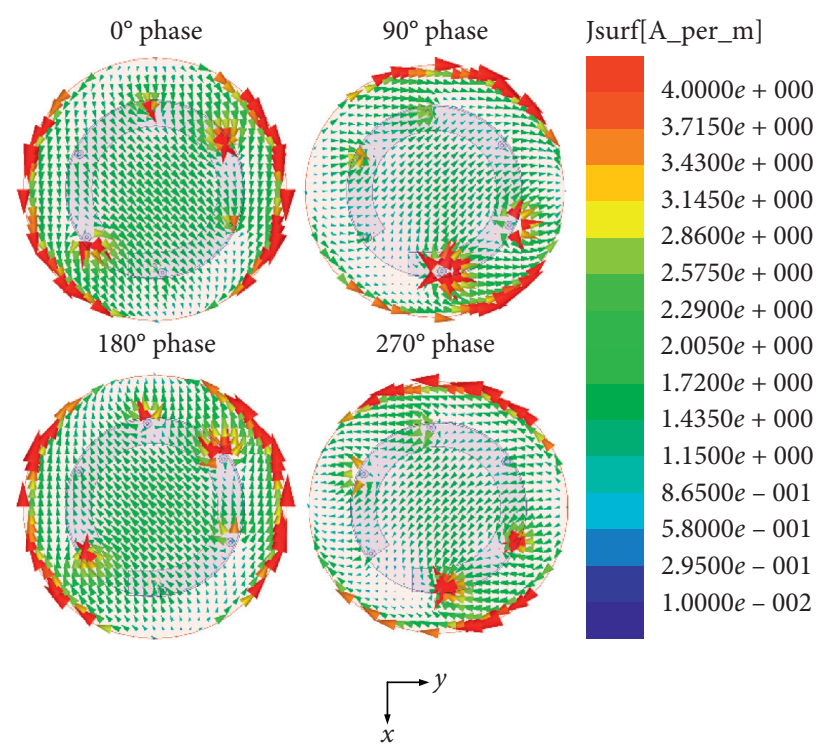

(a)
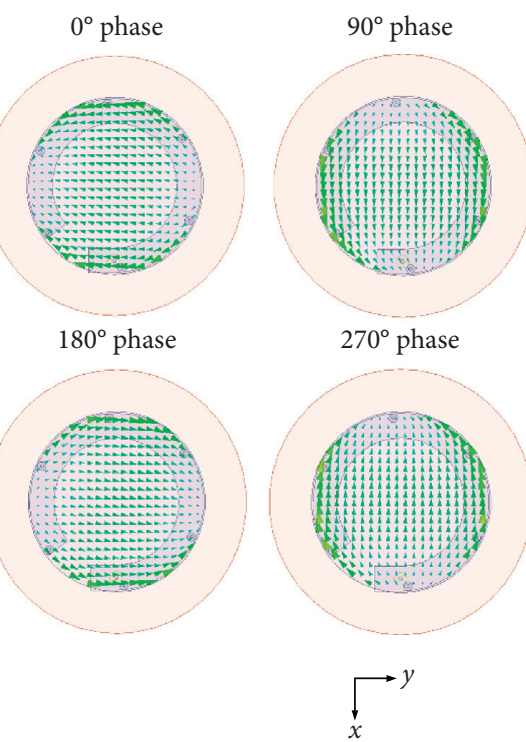

(b)

FIgURE 12: The surface current distribution on (a) patch 1 and (b) patch 2 at $1.91 \mathrm{GHz}$.

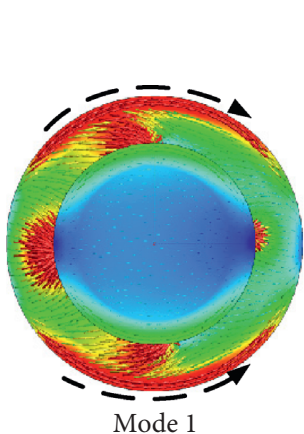

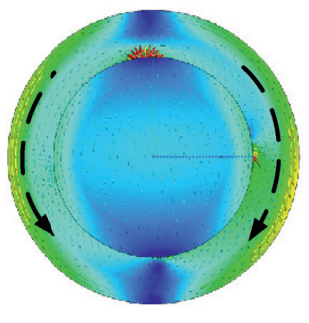

Mode 3

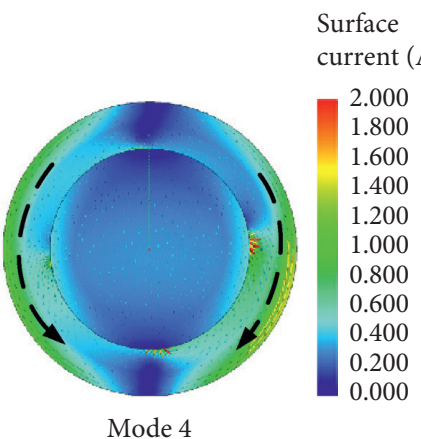

(a)

Surface current $(\mathrm{A} / \mathrm{m})$

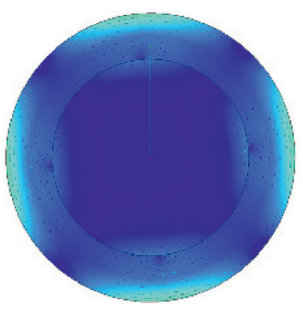

Mode 2

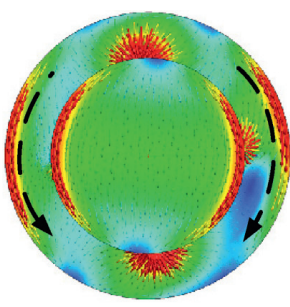

Mode 3

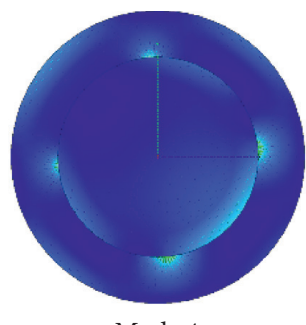

Mode 4

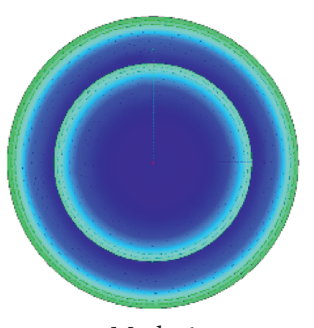

Mode 6

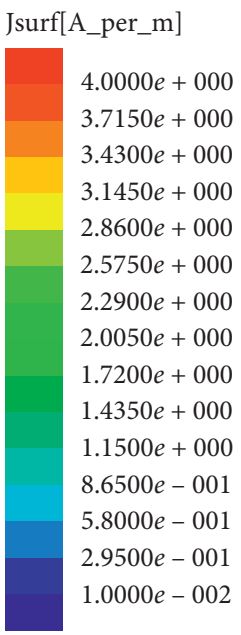

$4.0000 e+000$

$3.7150 e+000$

$3.4300 e+000$

$3.1450 e+000$

$2.8600 e+000$

$2.2900 e+000$

$2.0050 e+000$

$1.7200 e+000$

$1.4350 e+000$

$1.1500 e+000$

$8.6500 e-001$

$2.9500 e-001$

$1.0000 e-002$

(b)

FIgURE 13: Modal current distribution of the antenna with four probes at (a) $1.72 \mathrm{GHz}$ and (b) $1.96 \mathrm{GHz}$.

characteristics are obtained by modes 1, 3, and 4. However, modes 1 and 5 cannot be excited, and there is no mode that is orthogonal to mode 3 at $1.96 \mathrm{GHz}$, as shown in Figure 13(b). This leads to the deterioration of AR in the high-frequency band.

Figure 14 shows the modal current distribution of the proposed antenna with six probes at 1.72 and $1.96 \mathrm{GHz}$. We can see that mode 2 is orthogonal to modes 3 and 5 at $1.72 \mathrm{GHz}$, as well as mode 3 is orthogonal to mode 5 at $1.96 \mathrm{GHz}$. Thus, when the six probes are used, the antenna can obtain a wide AR bandwidth. Furthermore, mode 5 has intense current at patch 2 at $1.96 \mathrm{GHz}$. This indicates that patch 2 has a great influence on the CP radiation in the highfrequency band. 


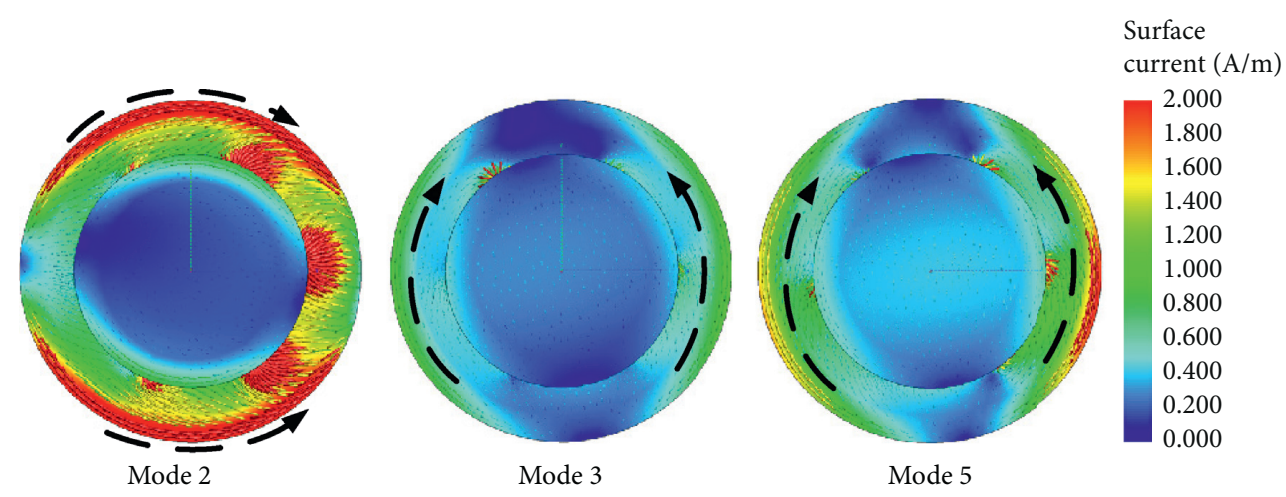

(a)

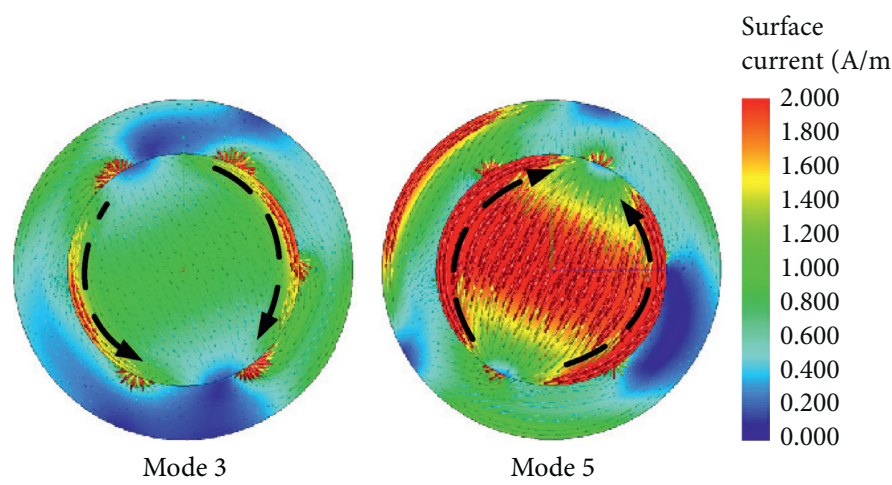

(b)

Figure 14: Modal current distribution of the antenna with six probes at (a) $1.72 \mathrm{GHz}$ and (b) $1.96 \mathrm{GHz}$.
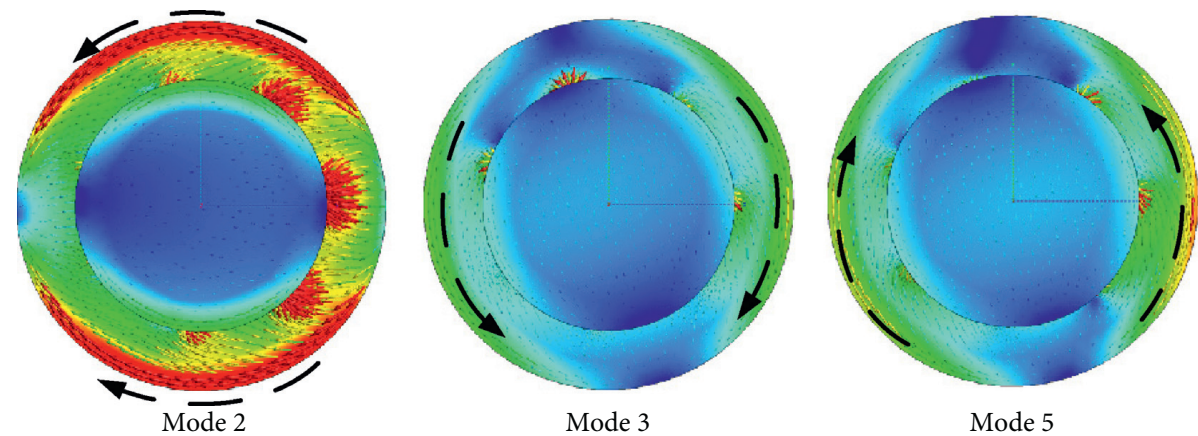

FIgURE 15: Modal current distribution of the antenna with seven probes at $1.72 \mathrm{GHz}$.

When seven probes with $\alpha=51.429^{\circ}$ are used, the AR in the low-frequency band has deteriorated. The mode current distribution at $1.72 \mathrm{GHz}$ is shown in Figure 15. It is shown that mode 2 is orthogonal to modes 3 and 5 . However, the current in modes 3 and 5 flows in opposite directions, which leads to the amplitude imbalance between the orthogonal modes, resulting in the deterioration of the AR.

\section{Measured Results and Discussion}

Figure 16 shows the fabricated prototype. $S_{11}$ was measured by using the Rohde \& Schwarz ZVT 8 vector network analyzer. Radiation patterns, gain, and AR were measured in an anechoic chamber.

The simulated and measured $S_{11}$ of the proposed antenna are shown in Figure 17(a). The measured impedance bandwidth for $S_{11} \leq-18 \mathrm{~dB}$ is $40.3 \%$ from 1.486 to 2.236 GHz. Figure 17(b) shows the simulated and measured boresight $\mathrm{AR}$. The measured bandwidth for $\mathrm{AR} \leq 3 \mathrm{~dB}$ is $31.6 \%$, covering 1.6 to $2.2 \mathrm{GHz}$. Figure $17(\mathrm{c})$ shows the measured boresight gain compared with the simulated result. The proposed antenna shows a stable measured gain of $8.89 \pm 0.87 \mathrm{dBic}$ within the $3-\mathrm{dB}$ AR bandwidth

The simulated and measured radiation patterns of two principal planes at $1.65,1.9$, and $2.15 \mathrm{GHz}$ are shown in 


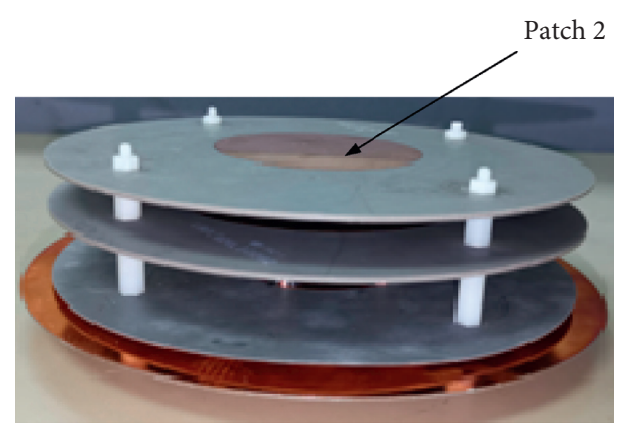

(a)

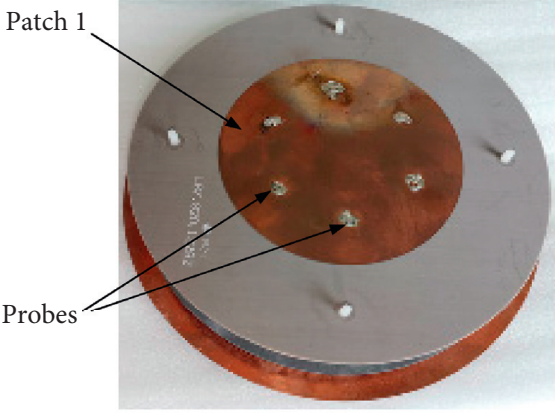

(b)

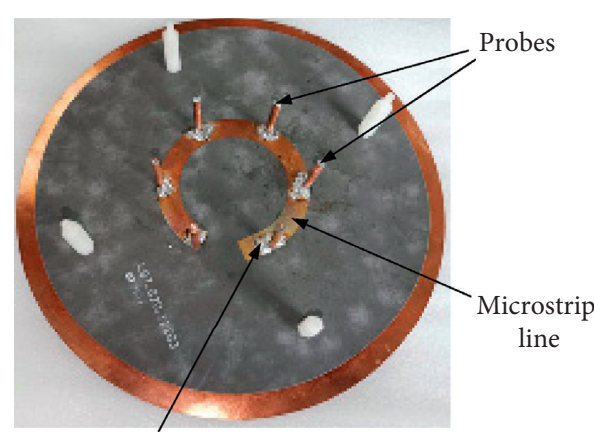

Central core of the coaxial line

(c)

Figure 16: Photograph of the fabricated antenna.

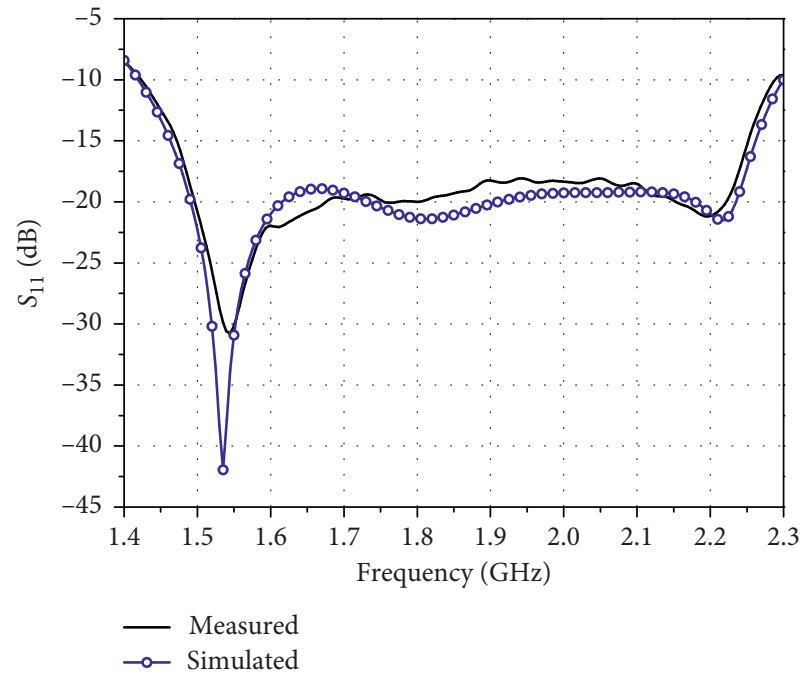

(a)

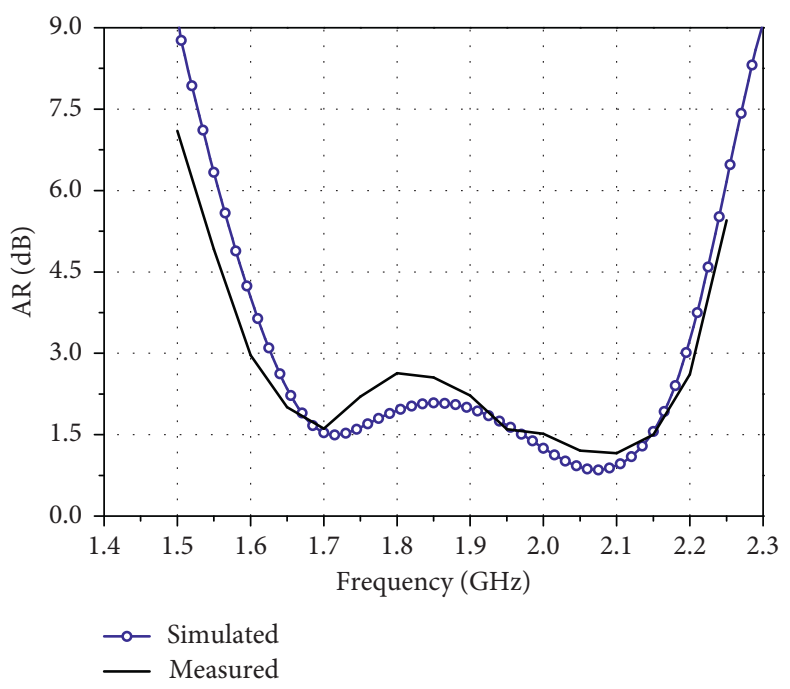

(b)

Figure 17: Continued. 


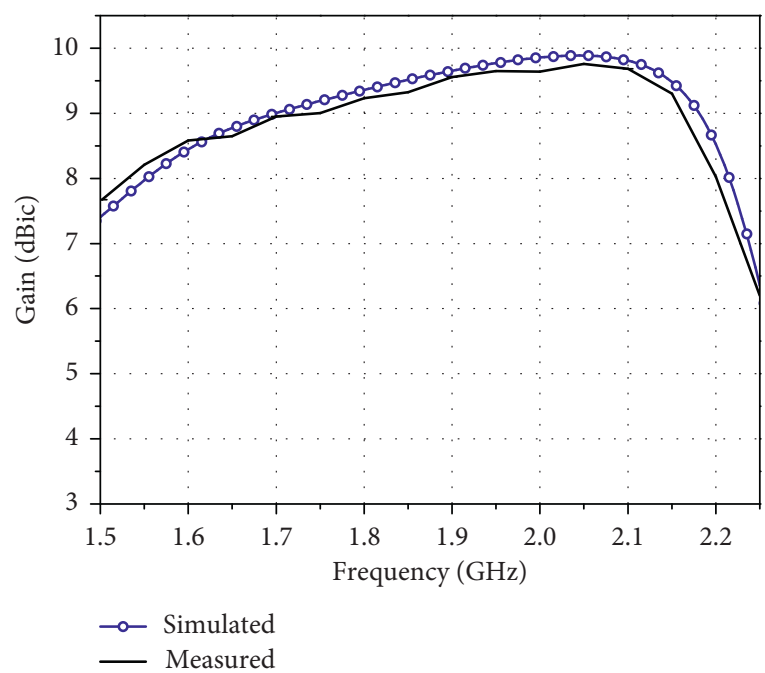

(c)

FiguRE 17: Measured and simulated results: (a) $S_{11}$, (b) AR, and (c) gain.
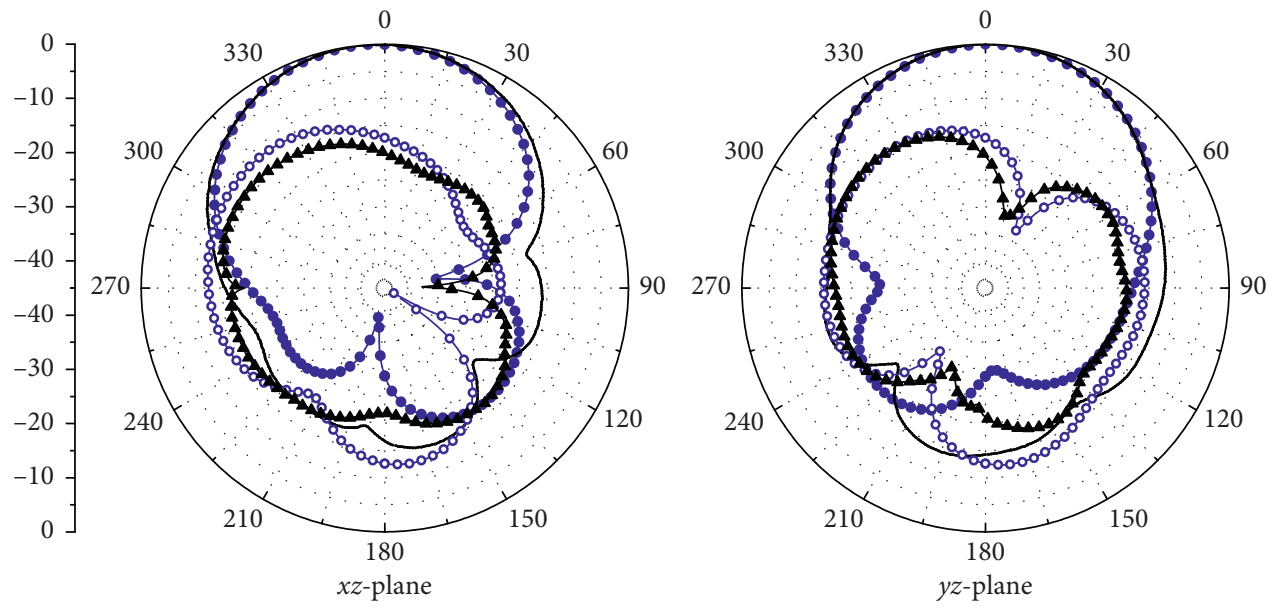

$\longrightarrow$ Simulated RHCP

-o- Simulated LHCP

— Measured RHCP

$\_$Measured LHCP

(a)
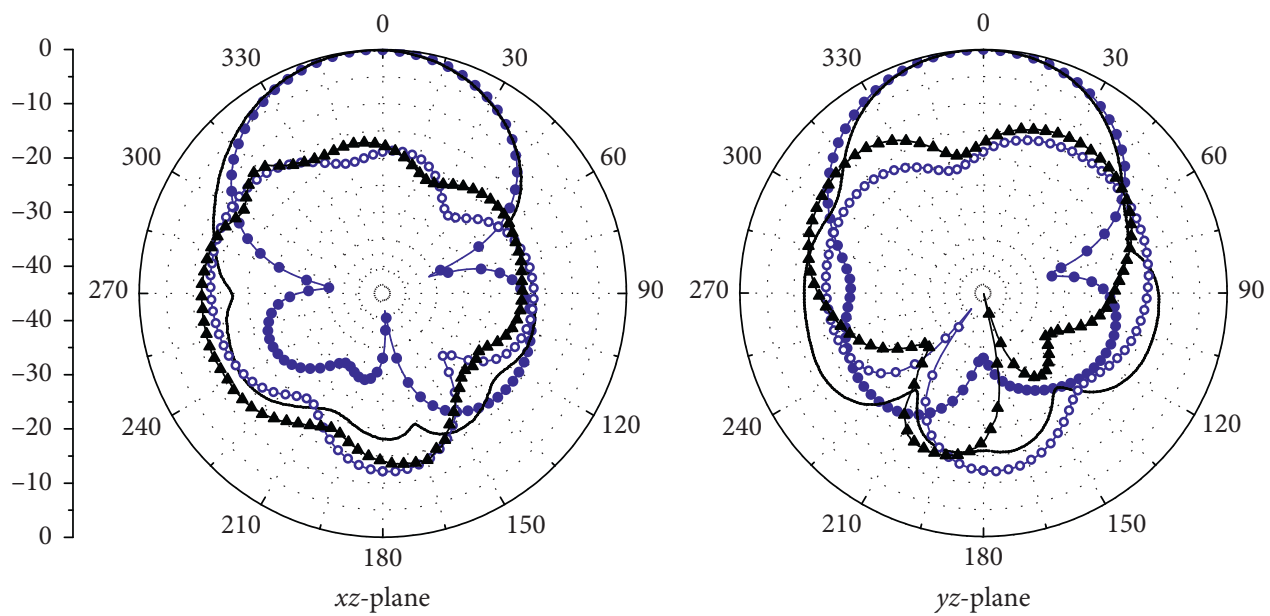

$\rightarrow-$ Simulated RHCP

-o- Simulated LHCP

Measured RHCP

$\_$Measured LHCP

(b)

Figure 18: Continued. 


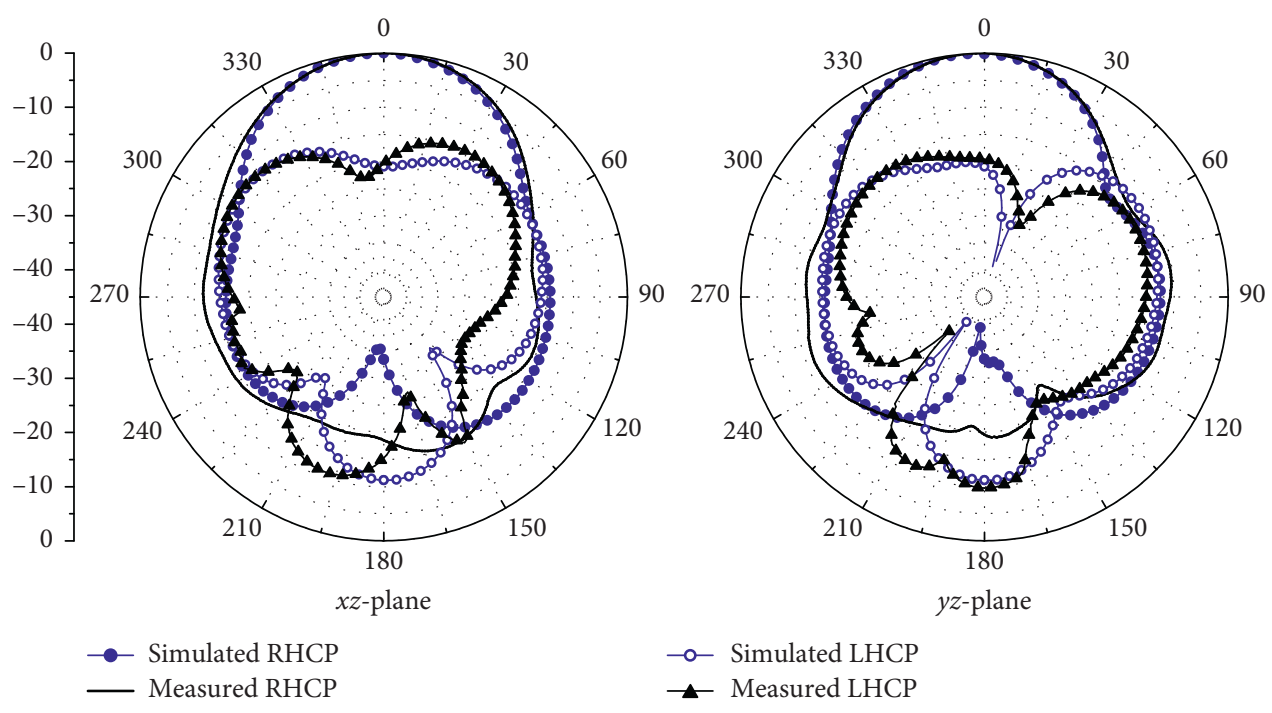

(c)

Figure 18: Measured and simulated radiation patterns of the proposed antenna at (a) 1.65, (b) 1.9, and (c) $2.15 \mathrm{GHz}$.

TABLE 2: Comparisons of the proposed and other CP antennas.

\begin{tabular}{|c|c|c|c|c|c|}
\hline Ref. year & $\begin{array}{l}\text { Dimension of patch } \times \text { height of } \\
\text { antenna }\left(\lambda_{A R d}\right)\end{array}$ & $\begin{array}{l}\text { Impedance } \\
\text { matching }\end{array}$ & Impedance bandwidth & 3-dB AR bandwidth & Gain (dBic) \\
\hline [5] 2014 & $\phi 0.55 \times 0.14$ & $S_{11} \leq-14 \mathrm{~dB}$ & $27 \%(1.45-1.9 \mathrm{GHz})$ & $16 \%(1.51-1.77 \mathrm{GHz})$ & About $7.7-8$ \\
\hline [9] 2014 & $0.24 \times 0.24 \times 0.13$ & $S_{11} \leq-10 \mathrm{~dB}$ & $42.3 \%(4.1-6.3 \mathrm{GHz})$ & $16.8 \%(5.05-5.98 \mathrm{GHz})$ & Peak gain: 6.7 \\
\hline [10] 2017 & About $0.27 \times 0.27 \times 0.07$ & $S_{11} \leq-10 \mathrm{~dB}$ & $38 \%(5-7.35 \mathrm{GHz})$ & $28.1 \%(5.32-7.06 \mathrm{GHz})$ & Peak gain: 8.4 \\
\hline [11] 2018 & $0.32 \times 0.32 \times 0.21$ & $S_{11} \leq-10 \mathrm{~dB}$ & $60.5 \%(1.5-2.8 \mathrm{GHz})$ & $31 \%(1.74-2.38 \mathrm{GHz})$ & $6.5 \pm 0.4$ \\
\hline $\begin{array}{l}*[12] \\
2017\end{array}$ & $0.45 \times 0.44 \times 0.11$ & $S_{11} \leq-10 \mathrm{~dB}$ & $25 \%(2.15-2.75 \mathrm{GHz})$ & $25 \%(2.1-2.7 \mathrm{GHz})$ & Peak gain: 8.3 \\
\hline [13] 2019 & $0.67 \times 0.45 \times 0.21$ & $S_{11} \leq-10 \mathrm{~dB}$ & $31.7 \%(2.35-3.3 \mathrm{GHz})$ & $15.3 \%(2.6-3.06 \mathrm{GHz})$ & $6.46-7.64$ \\
\hline $\begin{array}{l}* *[14] \\
2018\end{array}$ & $0.15 \times 0.15 \times 0.09$ & $S_{11} \leq-10 \mathrm{~dB}$ & $44.5 \%(4.64-7.3 \mathrm{GHz})$ & $27.5 \%(4.55-6 \mathrm{GHz})$ & Peak gain: 7.2 \\
\hline [15] 2014 & $0.31 \times 0.31 \times 0.19$ & $S_{11} \leq-10 \mathrm{~dB}$ & $24 \%(3.2-4.1 \mathrm{GHz})$ & $16 \%(3.5-4 \mathrm{GHz})$ & Peak gain: 9.6 \\
\hline [16] 2015 & $\phi 0.34 \times 0.16$ & $S_{11} \leq-10 \mathrm{~dB}$ & $29.7 \%(3-4.1 \mathrm{GHz})$ & $21.6 \%(3.3-4.1 \mathrm{GHz})$ & Peak gain: 8.6 \\
\hline [19] 2014 & $0.35 \times 0.35 \times 0.08$ & $S_{11} \leq-10 \mathrm{~dB}$ & $23.6 \%(2.09-2.65 \mathrm{GHz})$ & $17.9 \%(2.18-2.61 \mathrm{GHz})$ & About 8.5 \\
\hline [20] 2018 & $1.7 \times 1.7 \times 0.22$ & $S_{11} \leq-10 \mathrm{~dB}$ & $53.1 \%(3.9-6.72 \mathrm{GHz})$ & $15.6 \%(4.73-5.53 \mathrm{GHz})$ & $12.4-13.4$ \\
\hline Prop. & $\phi 0.45 \times 0.18$ & $S_{11} \leq-18 \mathrm{~dB}$ & $\begin{array}{c}40.3 \% \\
(1.486-2.236 \mathrm{GHz})\end{array}$ & $31.6 \%(1.6-2.2 \mathrm{GHz})$ & $8.02-9.76$ \\
\hline
\end{tabular}

$\lambda_{A R d}$ is the free-space wavelength at the starting frequency of the $3-\mathrm{dB}$ AR bandwidth. ${ }^{*} \lambda_{A R d}$ is the free-space wavelength at $2.15 \mathrm{GHz} .{ }^{* *} \lambda_{\text {ARd }}$ is the free-space wavelength at $4.64 \mathrm{GHz}$.

Figure 18. The $3-\mathrm{dB}$ beamwidth is more than $45^{\circ}$ for both planes.

Table 2 summarizes some key indicators of the proposed antenna and other wideband CP antennas. The antenna proposed in [14] is fed by a single feed point. The antenna proposed in [10] is fed equivalently by two feed points. To improve the AR of the antenna in [14], a reactive impedance surface is used. To improve the AR of the antenna in [10], an L-shaped parasitic patch and four parasitic patches are used. In [11], a wide $3-\mathrm{dB}$ AR bandwidth of $31 \%$ is achieved by generating an equivalent four-point feeding. It is observed that the more the feeding points, the easier it is to obtain a wider 3-dB AR bandwidth (27.5\% in [14], 28.1\% in [10], and $31 \%$ in [11]) and a wider impedance bandwidth $(44.5 \% \%$ in [14], 38\% in [10], and $60.5 \%$ in [11]). In this paper, an equivalent six-point feeding and a parasitic patch are used to extend the impedance and 3-dB AR bandwidths. Compared with the CP antennas in $[5,9-16,19,20]$, the proposed antenna has a wider 3-dB AR bandwidth and better impedance matching. The peak gain of the proposed antenna is $9.76 \mathrm{dBic}$, which is a good result. Although the antenna in [20] has a greater peak gain, the size is larger than that of the proposed antenna. The size of the proposed antenna is also competitive.

\section{Conclusion}

In this paper, a wideband CP antenna is studied and its advantages in impedance matching and $C P$ radiation performance are discussed in detail. By introducing six probes, a 
parasitic patch, and a split-ring microstrip line containing a rectangular section, the impedance bandwidth of $40.3 \%$ for $S_{11} \leq-18 \mathrm{~dB}$ and the $3-\mathrm{dB}$ AR bandwidth of $31.6 \%$ are achieved, which shows a great improvement in the operating bandwidth. A peak gain of $9.76 \mathrm{dBic}$ and unidirectional radiation patterns are also achieved.

\section{Data Availability}

The data used to support the findings of this study are included within the article.

\section{Conflicts of Interest}

The authors declare that they have no conflicts of interest.

\section{Acknowledgments}

This work was supported by the Young Elite Scientists Sponsorship Program by CAST, under Grant 2017QNRC001.

\section{References}

[1] X. Chen, G. Fu, S.-X. Gong, Y.-L. Yan, and W. Zhao, "Circularly polarized stacked annular-ring microstrip antenna with integrated feeding network for UHF RFID readers," IEEE Antennas and Wireless Propagation Letters, vol. 9, pp. 542$545,2010$.

[2] X. H. Tang, K. L. Lau, Q. Xue, and Y. L. Long, "Miniature circularly polarised patch antenna," Electronics Letters, vol. 46, no. 6, pp. 391-392, 2010.

[3] T.-N. Chang, J.-M. Lin, and Y. G. Chen, "A circularly polarized ring-antenna fed by a serially coupled square slotring," IEEE Transactions on Antennas and Propagation, vol. 60, no. 2, pp. 1132-1135, 2012.

[4] S. M. Kim and W. G. Yang, "Single feed wideband circular polarised patch antenna," Electronics Letters, vol. 43, no. 13, pp. 703-704, 2007.

[5] S. Fu, Q. Kong, S. Fang, and Z. Wang, "Broadband circularly polarized microstrip antenna with coplanar parasitic ring slot patch for L-band satellite system application," IEEE Antennas and Wireless Propagation Letters, vol. 13, pp. 943-946, 2014.

[6] K. L. Chung, "A wideband circularly polarized H-shaped patch antenna," IEEE Transactions on Antennas and Propagation, vol. 58, no. 10, pp. 3379-3383, 2010.

[7] Z. Wang, S. Fang, S. Fu, and S. Jia, "Single-fed broadband circularly polarized stacked patch antenna with horizontally meandered strip for universal UHF RFID applications," IEEE Transactions on Microwave Theory and Techniques, vol. 59, no. 4, pp. 1066-1073, 2011.

[8] X. H. Tang, Y. L. Long, H. Wong, and K. L. Lau, "Broadband circularly-polarised patch antenna with 3D meandering strip feed," Electronics Letters, vol. 47, no. 19, pp. 1060-1062, 2011.

[9] Q. W. Lin, H. Wong, X. Y. Zhang, and H. W. Lai, "Printed meandering probe-fed circularly polarized patch antenna with wide bandwidth," IEEE Antennas and Wireless Propagation Letters, vol. 13, pp. 654-657, 2014.

[10] W.-W. Yang, W.-J. Sun, W. Qin, J.-X. Chen, and J.-Y. Zhou, "Broadband circularly polarised stacked patch antenna with integrated dual-feeding network," IET Microwaves, Antennas \& Propagation, vol. 11, no. 12, pp. 1791-1795, 2017.
[11] Z. H. Tu, K. G. Jia, and Y. Y. Liu, "A differentially fed wideband circularly polarized antenna," IEEE Antennas and Wireless Propagation Letters, vol. 17, no. 4, pp. 861-864, 2018.

[12] Z.-Y. Zhang and K.-L. Wu, "A circularly polarized table-like air patch antenna with four grounded metal legs," IEEE Antennas and Wireless Propagation Letters, vol. 16, pp. 190193, 2017.

[13] Z. Li, J. Liu, and Y. Long, "A quasi-magnetic-electric circularly polarized antenna with wide bandwidth," IEEE Antennas and Wireless Propagation Letters, vol. 18, no. 10, pp. 2145-2149, 2019.

[14] J. Chatterjee, A. Mohan, and V. Dixit, "Broadband circularly polarized $\mathrm{H}$-shaped patch antenna using reactive impedance surface," IEEE Antennas and Wireless Propagation Letters, vol. 17, no. 4, pp. 625-628, 2018.

[15] C. Zhang, X. Liang, X. Bai, J. Geng, and R. Jin, “A broadband dual circularly polarized patch antenna with wide beamwidth," IEEE Antennas and Wireless Propagation Letters, vol. 13, pp. 1457-1460, 2014.

[16] C. Zhang, J. Geng, B. Zhou, X. Liang, and R. Jin, "A broadband single-feed circularly polarized patch antenna with wide beamwidth," International Journal of Antennas and Propagation, vol. 2015, Article ID 740274, 10 pages, 2015.

[17] X. Liu, Y. Liu, and M. M. Tentzeris, "A novel circularly polarized antenna with coin-shaped patches and a ring-shaped strip for worldwide UHF RFID applications," IEEE Antennas and Wireless Propagation Letters, vol. 14, pp. 707-710, 2015.

[18] Z. N. Chen, X. M. Qing, and H. L. Chung, "A universal UHF RFID reader antenna," IEEE Transactions on Microwave Theory and Techniques, vol. 57, no. 5, pp. 1275-1282, 2009.

[19] J. Wu, X. Ren, Z. Wang, and Y. Yin, "Broadband circularly polarized antenna with L-shaped strip feeding and shortingpin loading," IEEE Antennas and Wireless Propagation Letters, vol. 13, pp. 1733-1736, 2014.

[20] C. Zhou and S. W. Cheung, "High-gain windmill-shaped circularly polarized antenna using the high-order mode and ground-edge diffraction," IEEE Antennas and Wireless Propagation Letters, vol. 17, no. 3, pp. 368-372, 2018. 